\title{
HUKUM DAN MASYARAKAT DALAM PERSPEKTIF SOSIOLOGI HUKUM
}

\author{
Khaidir Saleh, Mario Agusta, Weni \\ Dosen dan mahasiswa pada Fakultas Hukum Universitas Muara Bungo \\ Jl. Diponegoro No. 27 Kelurahan Cadika, Kecamatan Rimbo Tengah, \\ Kabupaten Bungo Telp/Fax (0747) 323310 Kode Pos 37214 \\ E-mail :umb101016@gmail.com
}

\section{Ringkasan}

Hukum dan masyarakat memiliki fungsi yang saling berkaitan. Fungsi hukum pada masyarakat adalah untuk mencegah konflik kepentingaan. Jika terjadi, maka hukum menjadi penyedia cara untuk menyelesaikannya berdasarkan kebijakan yang didasarkan pada norma yang berlaku. dengan keterkaitan hukum dan masyarakat, maka perbuatan masyarakat untuk main hakim sendiri akan terhindar. Semua persoalan dan konflik kepentingan yang ada di masyarakat harus diselesaikan melalui jalur hukum. Dari sinilah fungsi hukum dan masyarakat berkaitan. hukum mengandung unsur aturan perilaku manusia, sedangkan regulasi dipegang oleh badan resmi yang memiliki wewenang. Sementara untuk karakteristik yang melekat dalam hukum, menurutnya karena adanya perintah dan larangan. Larangan dan perintah harus dipatuhi dan dipatuhi oleh orang-orang dan adanya sanksi hukum yang ketat. Intinya hukum dimaksudkan untuk mengatur hubungan perilaku dan hubungan yang ada di masyarakat. Baik dilakukan oleh satu orang dengan orang lain, individu dengan negara dan mengatur hubungan institusi yang ada di negara tersebut. dengan hukum, kekuasaan dilaksanakan sesuai dengan fungsi dan tujuan hukum itu sendiri.

Kata Kunci: Hukum, Masyarakat, Sosiologi Hukum

\section{PENDAHULUAN}

Ilmu tentang hubungan timbal balik antar masyrakat ini dinamakan sosiologi yang kajian nya sangat menarik untuk di bahas. Aristotoles yang terkenal dengan teotrinya"Zoom politicon" mengatakan bahwa manusia adalah mahkluk sosial, berdasarkan teori kita lihat bagaimana individu tumbuh menjadi manusia yang senang dan cenderung hidup berkelompok. Sosiologi hukum katanya terbagi menjadi 2 yaitu sosiologi dan hukum, sosio artinya masyarakat logi itu keilmuan maka jika digabung akan menjadi masyarakat yang berilmu hukum.

Dari pendapat para ahli di atas dapat kita simpulkan bahwa sosiologi adalh ilmu yang mempelajari tentang hubungan timbale balik dan seluruh laidah baik struKtur sosial,pranata sosial, kelompok sosual yang ada dalam kehidupan masyrakat. Teleh di ketahui, bahwa sosiologi adalah suatu ilmu sosial dan bukan merupakan ilmu pengetahun alam ataupun ilmu pengetahuan kerohanian. Soiologi bukan merupakan disiplin yang normatif, akan teteapi adalah suatu disiplin yang kategoris artinya sosiologi memebatsai siri dari apa yang terjadi dewasa ini bukan pada apa yang seharusnya terjadi.

\section{PERMASALAHAN}


Bagaimana ruang lingkup Hukum dan Masyarakat dalam perspektif sosiologi hukum?

\section{PEMBAHASAN}

Sosiologi hukum pada hakikatnya lahir dari hasil-hasil pemikiran para ahli baik di bidang filsapat hukum,ilmu dan maupun sosiologi. Salah satu tugas sosiologi hukum adalah mengungkapkan sebat atau latar belakang tombulnya ketimpangan antara tata tertip masyrakat yang di cita-citakan dengan keadaan masyrakat yang ada dalam kenyataan adapun pengrtian sossiologi hukum menurut para ahli:

a, Soerjono Soerkanto

sosiologi hukum adalah suatu cabang ilmu pengetahuan yang secara analitis dan empiris menganalisa atau mempelari hubungan timbaql balik antara hukum dengan gejala-gejala lain.

b, Satjipto Raharjo

sosiologi hukum adalah pengatuhuan hukum terhadap pola prilaku mayrakat dalam kontek sosial.

Dengan memepelajari sosiologi hukum kita dapat mengetahui bahwa tujuan hukum adalah untuk memeberikan kepastian hukum .kemanfa,atan dan keadilan kapega masyarakat serta dalam kehidupan bermasyarakat. Struktur sosial dapat di defenisikan seabagai tatanan sosial dalam kehidupan bermasyrakat yang di dalamnya terkandung hubungan timbal balik antara status dan peranan debgab batas-batas perangkat unsur-unsur sosial yang menunjuk pada suatu keteraturan perilakau, sehingga dapat memeberikan bentuk sebagai suatu masyarakat.

Pranata sosial tidak di bentuk sercara tiba-tiba,tetapi melalui proses yang panjang, proses timbulnya lembaga kemasyrakatan terkait dengan:

1.norma-norma masyrakat,supaya hubungan antar manusia sesuai yang di harapkan, maka di susun norma-norma masyarakat.

2.pengendalian sosial (sosial control),pengandalian sosial dapat di artikan sebagai segala proses baik

yang di rencanakan maupun tidak yang bersifat mengajak,mendidik, tau bahkan memeaksa warga-warga masyrakat agar mematuhi norma-norma berlaku.

Ciri-ciri stuktur sosial

a.struktur sosial mengacu pada hubunganhubungan sosial yang pokok yang dapat memberikan bentuk dasar pada masyrakat.

b. struktur sosial mencakup hubungan secara individu-individu pada saat tertentu,oleh karena itu maka struktur sosial dapat di sebut sebagai aspek non proses dari sitim sosial, intinya adalh situasi statis dari sistim sosial.

c.struktur sosial merupakan seluru kebudayaan masyarakat yang dapat di lihat dari sudut pandang teoretis.

d.strujtur sosial merupakan realitas sosial yang bersifat statis atau kenyataan yang membeku, sehingga dapat di lihat kerangka tatanan dari sebagai bagian turbuhnya yang berbentuk struktur.

\section{Masyarakat Sebagai Mahluk Sosial}

Menurut Aguste Comte sosiologi merupakan ilmu pengetahuan yang mempeleajari manusia sebagai mahluk yang mempunyai naluri unuk senantiasa hidup bersama dengan sesamanya. Masyarakat terbentuk atas dasar hakikat individu, apabila kepentingan individu berubah maka masryrakatpun akan berubah.

Seabagai indudvidu manusia cenderung membutuhkan orang laen dalam proses kehidupan sehingga membentuk interaksi sosial dengan sesamanya. Kumpulan individu-individu yang saling berinteraksi sosial ini dinamakan masyarakat. Adapun yang menyebabkan manusia selalu hidup bermasyarakat antara lain karena adanya dorongan kesatuan biologis yang terdapat dalam naluri manusia misalanya: 
Vol 1, No 2 Agustus - Desember 2020

a.hasrat untuk memenuhi keperluan makan dan minum

b.hasrat untuk memebela diri

c.hasrat untuk mengadakan keturunan.

Manusia sebagai mahluk sosial adalah manusia yang senantiasa hidup dengan manusia lainnya (masyarakat).

\section{Hubungan Hukum dan Masyarakat}

Keluarga merupakan lingkungan manusia yang pertama dan utama. Kelompok berikutnya adalah kelompok pertemanan,pergaulan,kelompok pekerja dan masyarakat secara luas.hukum sebagai kaidah hadir untuk mengatur pola prilaku masyarakat terseabut,hukum bertujuan menjamin kepastian hukum dalam masyarakat. Agar tujuan kaidah tersebut dapat terwujud dengan semestinya, atau sesuai dengan harapan seluruh anggota masyarakat/Negara maka harus ada kepatuhan kepada kaidah hukum tersebut. Adanya kesadaran hukum menyebabkan orang bisa memisahkan antara sesuai dengan hukum (perilaku yang benar) dengan yang tidak sesuai dengan hukum (periilaku menyimpang).fungsi hukum sebagai alat pengendali dalam kehidupan bermasyarakat adalah untuk menetapkan tingkah laku mana ysng di anggap merupakan penyimpangan terhadap aturan hukum, dan apa sanksi atau tindakan yang dilakukan oleh hukum jika terjadi penyimpangan tersebut. Kemudian hukum sebagai rekayasa sosial,masyarakat dalam menjalani kehidupan cenderung berubah kemudian perubahan-perubahan dalam masyarakat ini di harapkan hukum mampu menjalaskan fungsinya menyesuaikan kehidupan masyakarat pada inovasi, nilai pada tujuan sebagai perekayasa sosial.

\section{KESIMPULAN}

Hukum dan masyarakat memiliki hubungan timbal balik yakni dimana ada hukum disitu ada masyarakat. Hukum ada untuk mengatur kehidupan bermasyarakat agar masyarakat memiliki kesadaran hukum mengenai pedoman norma tentang perbuatan yang boleh dilakukan dan perbuatan yang merupakan penyimpangan dalam kehidupan masayarakat.

\section{DAFTAR PUSTAKA BUKU}

Abdulsyani, 2012, Sosiologi Skematika, Teori dan Terapan, Bumi Aksara, Jakarta.

Budiman, Arief, 1996, Teori Negara, Kekuasaan dan Ideologi, Gramedia, Jakarta

Hermanto dan Winarno, 2011, Ilmu Sosial dan Budaya Dasar, Bumi Aksara, Jakarta

Iswara, Fred, 1964, Pengantar Ilmu Politik, Dwiwantara, Jakarta

Salman, Otje Dan Susanto,2004, F. Anton. Beberapa Aspek Sosiologi Hukum, PT. Alumni: Bandung

Soekamto Soerjono, Sosiologi Suatu Pengantar, Raja Grafindo Persada, Jakarta.

Soekanto, Sarjono, 1998, Pokok-Pokok Soisologi Hukum: PT. Raja Grafindo Persada: Jakarta

\section{JURNAL}

Iman Pasu Marganda Hardianto Purba, Penguatan Budaya Hukum Masyarakat Untuk Menghasilkan Kewarganegaraan Transformatif, Jurnal Civics, Vol. 14, Nomor 2, Oktober 2017 
Santoso Agus, Kajian Hubungan Timbal Balik Antara Politik Dan Hukum
Tony Hanoraga, Dialektika Hubungan Hukum Dan Kekuasaan, 